\title{
Heavy Metal Content Analysis and Toxicity Assessment of Oil-Based Drilling Mud using Zebrafish Embryos
}

\author{
Nanthini Sridewi, Siti Nurbariah, Syahida Ahmad
}

Aim: Used oil-based drilling muds (OBDMs) are toxic to marine organisms due to the fluid's complex chemical nature. The illegal dumping of used OBDMs is still rampant in many parts of the world despite of the stringent laws and regulations pertaining to its disposal. To date, study of the assessment of heavy metal content in used OBDMs from the Malaysian oil and gas industry has been limited. Furthermore, the study of the toxic effect of OBDMs using a zebrafish embryo model has never been reported before. Therefore, in this research, the used oil-based drilling muds (OBDMs) were analyzed for their heavy metal content and toxicity against Zebrafish embryos. Methods: Used OBDMs were collected from an Anchor Handling Tug Supply (AHTS) vessel mud tank from Kemaman, Terengganu. The heavy metal content in the mud was analyzed using ICP-AES. Zebrafish embryos were exposed to OBDMs of varying concentrations (i.e., $0.25 \mathrm{mg} / \mathrm{ml}, 0.125 \mathrm{mg} / \mathrm{ml}, 0.06 \mathrm{mg} / \mathrm{ml}, 0.03 \mathrm{mg} / \mathrm{ml}, 0.015$

\section{KEY WORDS}

$\sim$ Oil-based drilling muds

$\sim$ Heavy metal

$\sim$ Toxicity

$\sim$ Zebrafish embryo

$\sim$ Embryotoxicity

$\sim$ Teratogenicity

Universiti Pertahanan Nasional Malaysia, Kuala Lumpur, Malaysia

e-mail: nanthini@upnm.edu.my

doi: 10.7225/toms.v10.n02.w06

This work is licensed under (cc) BY

Received on: 20.05.2021 / Revised on: 06.06.2021 / Accepted on:06.07.2021/Published online: 28.08 .2021 $\mathrm{mg} / \mathrm{ml}, 0.0076 \mathrm{mg} / \mathrm{ml}, 0.0034 \mathrm{mg} / \mathrm{ml}$ and $0.0019 \mathrm{mg} / \mathrm{ml}$ ). The toxicity and teratogenicity of the mud on zebrafish embryos were assessed every 24 hours, for 96 hours, using endpoints like embryo mortality, heart rate and hatching rate. Results: The heavy metal content of used OBDMs had the highest concentration of barium (Ba) 2360 ppm, followed by lead (Pb) 120 ppm, zinc (Zn) 104 ppm, arsenic (As) 9 ppm, and chromium (Cr) 16 ppm, with cadmium ( $\mathrm{Cd}$ ) concentration of less than $1 \mathrm{ppm}$ being the lowest. The $\mathrm{Ba}(2360 \mathrm{mg} / \mathrm{L})$ concentration in the OBDM sample exceeded the concentration of $\mathrm{Ba}$ in normal marine sediment reported to be around $2000 \mathrm{mg} / \mathrm{L}$. The $96 \mathrm{~h} \mathrm{LC}_{50}$ of the OBDM in zebrafish embryos was reported to be $0.005 \mathrm{mg} / \mathrm{mL}$ (5 ppm). Zebrafish embryos that were exposed to high concentrations of OBDMs exhibited a lower hatching rate and reduced heart rate than the control group. Conclusion: The findings of this study are indicative of the highly toxic nature of used OBDMs and its dosage-dependent teratogenicity effects on zebrafish embryo. Knowledge of the potential environmental impacts of OBDMs released into the marine environment can be the basis for prudent decision-making that will help minimize environmental damage.

\section{INTRODUCTION}

The process of oil and liquefied natural gas production involves several major processes, such as exploration, well development, production, and site abandonment (Doric and Dimovski, 2018). During well development, drilling fluid is circulated in the borehole to facilitate a cost-effective and efficient drilling operation (Gandhi and Sarkar, 2016). 
There are three main categories of drilling fluids, i.e. waterbased muds that can be dispersed and non-dispersed, nonaqueous muds, usually called oil-based muds, and syntheticbased muds (Seyedmohammadi, 2017). These drilling muds are continuously circulated between the well and the platform through a riser pipe. Mud is used to maintain pressure and wall stability, as an agent that cools and lubricates the drill bit and to carry rock drill cuttings generated during the drilling process away from the cutting head to the platform (Ahmed et al., 2020; Hossain and Islam, 2018).

Environmental problems associated with complex drilling fluids in general, and oil-based drilling mud (OBDM) in particular, are among the major concerns of communities worldwide (Gamal et al., 2019). The discharge of hole fluid or cuttings generated with OBDMs is not permitted in most offshore-drilling areas (Cordes et al., 2016; Kark et al., 2015). All such drilled cuttings and waste fluids are processed and shipped to shore for disposal. However, the risks of unregulated offshore disposal or accidental spillage is still a major concern, especially in areas outside national jurisdiction (Sharif et al., 2017).

The awareness of high heavy metal content of OBDMs and the fact that they bioconcentrate and biomagnify across the food chain emphasize the importance of extrapolating the toxicity of OBDMs to humans. Although laboratory studies on rodents can be a reliable tool for this purpose, they are often expensive and involve ethical concerns. A better alternative to rodents as model organisms in toxicological studies are adult and embryonic zebrafish.

Embryos in particular have the added advantage that their developmental stages can be observed directly due to the transparent nature of the eggs (Chahardehi et al., 2020). Furthermore, as zebrafish and humans have $70 \%$ of the DNA in common, this organism is more suitable for the extrapolation of toxicity in humans (Chanika et al., 2019).

To date, though various studies on OBDM toxicity have been conducted on fish, crustaceans and mollusks, no studies have been conducted on adult zebrafish or their embryos. Therefore, in this study, we attempted to evaluate median lethal concentrations (LC50), as well as potential developmental and teratogenic effects of the OBDM on zebrafish embryos, using samples collected from an Anchor Handling Tug Supply (AHTS) vessel mud tank from Kemaman, Terengganu, Malaysia. The heavy metal content of the used OBM sample was also analyzed.

\section{MATERIALS AND METHOD}

\subsection{Sample Acquisition}

The used OBDM samples were collected from the mud tank of an AHTS vessel, from the oil field at Kemaman, Terengganu, Malaysia. The jack-up rig has a drilling depth capacity of 30,000 feet and can operate at water depths of up to 400 feet. Drilling mud samples were collected using a grab sampler and transferred into high-density polyethylene bags. The samples were preserved in an icebox before being transported to the laboratory for further analyses.

\subsection{Heavy Metal Analysis of the Used OBDM Medium}

The used OBDM samples were subjected to acid digestion using a combination of sulphuric acid ( $\mathrm{H} 2 \mathrm{SO} 4)$ and nitric acid (HNO3) at a 3:1 ratio. The analysis of arsenic (As), barium (Ba), cadmium (Cd), chromium ( $\mathrm{Cr}$ ), lead $(\mathrm{Pb})$ and zinc ( $\mathrm{Zn}$ ) content was conducted using Inductively Coupled Plasma-Atomic Emission Spectrometry (ICP-AES) according to USEPA 6010B.

\subsection{Serial Dilution of Used OBDM}

A solvent of $\mathrm{H} 2 \mathrm{SO} 4$ : $\mathrm{HNO} 3$ mixed at a 3:1 ratio $(4 \mathrm{ml})$ was combined with $6 \mathrm{ml}$ of Danio-SprintM Embryo Media $(0.1 \%$ DMSO) and regulated to $\mathrm{pH}$ 7.2. The mixture was used to prepare a stock solution of the used OBDM samples with the final concentration of $5 \mathrm{mg} / \mathrm{ml}$. The stock solution was serially diluted with Danio-SprintM Embryo Media to obtain a series of concentrations ranging from $0.25 \mathrm{mg} / \mathrm{ml}, 0.125 \mathrm{mg} / \mathrm{ml}, 0.06 \mathrm{mg} /$ $\mathrm{ml}, 0.03 \mathrm{mg} / \mathrm{ml}, 0.015 \mathrm{mg} / \mathrm{ml}, 0.0076 \mathrm{mg} / \mathrm{ml}$ and $0.0034 \mathrm{mg} / \mathrm{ml}$ to $0.0019 \mathrm{mg} / \mathrm{ml}$.

\subsection{Used OBDM Toxicity Testing Using Zebrafish Embryos}

Zebrafish embryos were purchased from Danio Assay Laboratories Sdn. Bhd. The zebrafish embryotoxicity test was carried out in keeping with Zhu et al. (2008). Embryo viability was checked under a stereomicroscope to make sure they are in the pharyngula stage [ $24 \mathrm{hpf}$ (hours post-fertilization)]. Only healthy embryos were selected and transferred into a 96-well plate. The 
embryo media in each well was replaced with $100 \mu \mathrm{L}$ of fresh Danio-SprintM Embryo Media followed by the addition of $100 \mu \mathrm{L}$ of the pre-prepared serial dilution of the sample. The treated embryo plates were incubated at $28 \pm 2^{\circ} \mathrm{C}$ and observed under an inverted stereomicroscope under 100x magnification, every 24 hours for 96 hours. Toxicity endpoint was determined through the assessment of mortality, heartrate and hatching rates. The LC50 value was calculated using probit analysis to compare the survival of treated embryos with the control group.

\section{RESULTS AND DISCUSSION}

\subsection{Heavy Metal Content in Used OBDM}

The heavy metal content of used drilling mud largely depends on the type of drilling mud used, as well as on the geological factors of the oil shale deposits. The OBDM sample in this study contains a remarkably high concentration of $\mathrm{Ba}(2360$ $\mathrm{mg} / \mathrm{L}$ ) [Table 1], exceeding the concentration of $\mathrm{Ba}$ in normal

Table 1.

Concentration of heavy metals in the used OBDM sample.

\begin{tabular}{lll} 
Heavy Metal & Limit of Reporting (LOR) & Concentration $(\mathrm{mg} / \mathrm{L})$ \\
\hline Arsenic & 1 & 9 \\
\hline Barium & 5 & 2360 \\
\hline Cadmium & 1 & $\bigotimes 1$ \\
\hline Chromium & 1 & 16 \\
\hline Lead & 1 & 120 \\
\hline Zinc & 1 & 104 \\
\hline
\end{tabular}

marine sediment, reported to be around $2000 \mathrm{mg} / \mathrm{L}$ (Neff, 2008).

A similar observation was made in many previous studies, regardless of the type of drilling mud tested. The source of $\mathrm{Ba}$ is Barite (BaSO4), which is often added to drilling muds as a weighting agent to counteract pressure in geological formations being drilled, preventing a blowout (Alfa et al., 2019; Neff, 2008). Lead (120 mg/L) and zinc (104 mg/L) concentrations are approximately $10 \mathrm{x}$ higher than the average content of these metals in uncontaminated marine sediment which has the lead and zinc content of (10-33 ppm) and (27-88 ppm) respectively. The bioconcentration of these heavy metals poses a serious threat to marine organisms due to their persistent nature and bioavailability.

\subsection{Toxicity Assessment of Used OBDM Using Zebrafish}

The embryotoxicity effects of OBDM samples in the first $96 \mathrm{hrs}$. of zebrafish development revealed significant toxicity of the samples even at low sample concentrations. As sample concentrations increased, the survival of zebrafish embryos decreased, reaching $100 \%$ mortality at OBDM concentration of $0.125 \mathrm{mg} / \mathrm{mL}$ after $96 \mathrm{hrs}$. of exposure (Table 2).
Table 2.

The mortality rate of zebrafish embryos after $96 \mathrm{hrs}$. of exposure to varying OBDM concentrations.

\begin{tabular}{ll}
$\begin{array}{l}\text { OBDM Concentration }(\mathrm{mg} / \\
\mathrm{mL})\end{array}$ & Mortality Rate (\%) \\
\hline 0.125 & 100 \\
\hline 0.06 & 91.67 \\
\hline 0.03 & 83.33 \\
\hline 0.015 & 66.67 \\
\hline 0.0076 & 50 \\
\hline 0.0034 & 33.33 \\
\hline 0.0019 & 16.67 \\
\hline Control (EM with 0.2\% DMSO) & 8.33 \\
\hline
\end{tabular}


The $\mathrm{LC}_{50}$ value of OBDM in zebrafish embryos was found to be $0.005 \mathrm{mg} / \mathrm{mL}$ (5 ppm). This OBDM toxicity for zebrafish embryos is comparable to that of hydroquinone ( $4.40 \pm 0.33 \mathrm{ppm})$ and mercuric chloride $(0.27 \mathrm{ppm})$ as reported in literature (Ahmad et al., 2020). The hatching rate of zebrafish larvae was observed between 48 hpf - 96 hpf (Figure 1). Embryos in the control group had the hatching rate of over $80 \%$. As OBDM concentrations increased, decreasing embryo hatching rates were observed. No hatching was observed at the OBDM concentration of $0.125 \mathrm{mg} /$ $\mathrm{ml}$, corresponding to $100 \%$ embryo mortality.

Besides, no premature or delayed hatching was observed in either the control or test groups. Zebrafish mortality occurred in the embryonic stage and hatched larvae survived $96 \mathrm{hrs}$. of exposure to varying OBDM concentrations.

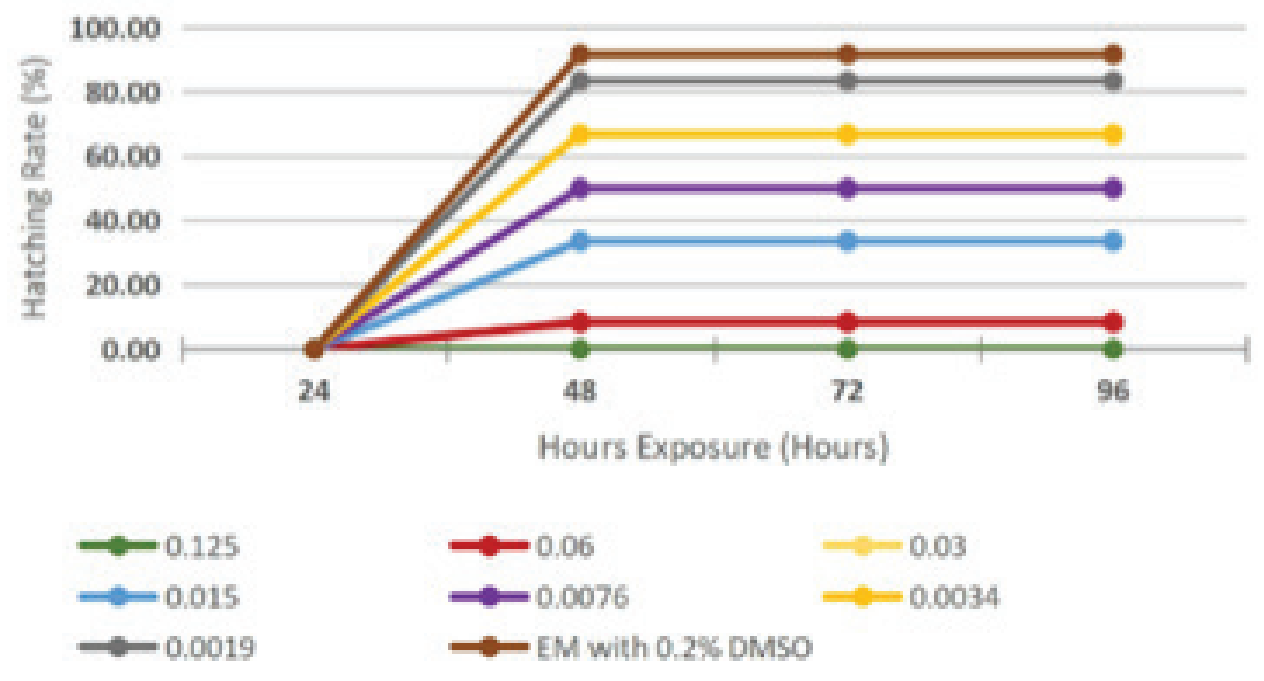

Figure 1.

Effect of varying OBDM sample concentrations on the hatching rate of zebrafish larvae over a 96-hour exposure period.

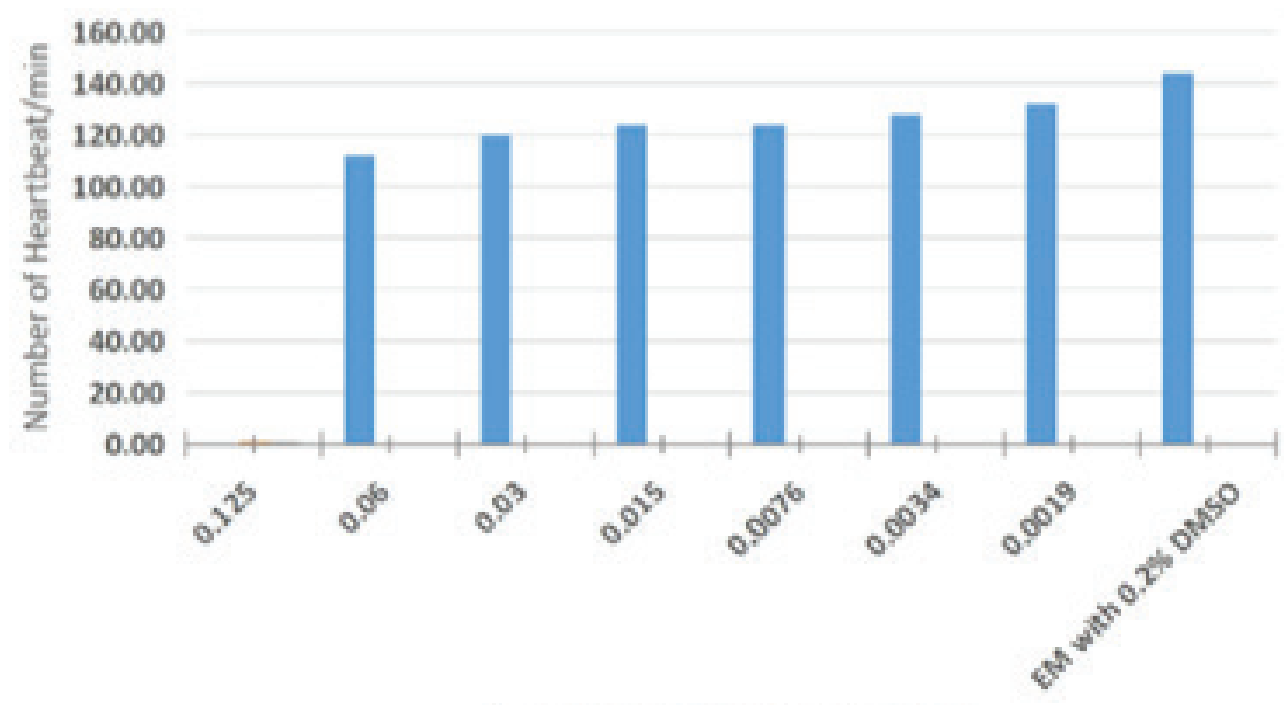

Sample Concentrations (ug/ $\mathrm{mL}$ )

Figure 2 .

Effect of varying OBDM sample concentrations on the heartrate of zebrafish larvae after 96-hour exposure. 
Zebrafish embryo heartbeat stopped as OBDM concentrations increased as compared to embryos in the control group (Figure 2). Zebrafish embryos in the control group had the heartrate of $140-145$ beats per minute (bpm). OBDM concentration of $0.06 \mathrm{mg} / \mathrm{mL}$ caused the heartbeat of zebrafish embryos to drop to $110 \mathrm{bpm}$. In a previous study, ethanol exposure during embryogenesis was found to obstruct cardiogenesis, and even cause defects in heart chamber and valve morphogenesis of juvenile zebra fish (Sarmah and Marrs, 2013). The severity of the defects varies depending on exposure duration, embryo's developmental stage and pollutant concentrations.

Please note that the cellular frameworks of zebrafish and mammalian hearts are comparable. This may indicate potential cardiogenic effects of exposure of marine mammals and humans to high OBDM concentrations that could be transferred across the marine food chain. Several important genes and regulatory networks involved in mammalian cardiogenesis have also been found in the regulatory networks essential for zebrafish cardiogenesis. Moreover, both the human fetal heartrate (130$170 \mathrm{bpm}$ ) and cardiovascular physiology more closely resemble that of the zebrafish than of the rodents (Sarmah and Marrs, 2016).

\section{CONCLUSION}

The findings of this research indicate that used OBDM is highly toxic due to its low LC50 value (5 ppm), owing to the higher concentration of heavy metals such as $\mathrm{Ba}, \mathrm{Pb}$ and $\mathrm{Zn}$ in this sample in comparison to uncontaminated marine sediment. An increase in OBDM sample concentrations caused a reduction in zebrafish embryo survival rate, hatching rate and heartrate. These findings can be used to extrapolate the potential toxicity of OBDM to marine mammals, as well as humans, since zebrafish have a striking resemblance to mammalian cardiogenesis and human genetics. Strict regulations must be in place to regulate the proper disposal of used OBDMs to avoid their negative effects on the marine environment. Effective mitigation measures should be taken in case of accidental spillage of this hazardous material in the marine environment or whenever an unauthorized discharge is detected. Apart from this, countries involved in active oil and gas exploitation should focus on the development and use of low-toxicity, environmentally-friendly drilling mud additives.

\section{ACKNOWLEDGEMENT}

The authors would like to thank Mr. Che Mohd Hakiman Che Maail for his guidance in conducting the zebrafish embryotoxicity studies.

\section{REFERENCES}

Ahmad, F. et al., 2020. Effect of Pesticides and Metals on Zebrafish Embryo Development and Larval Locomotor Activity. bioRxiv Preprint.

Ahmed, N., Alam, M.S. \& Salam, M.A., 2020. Experimental analysis of drilling fluid prepared by mixing iron (III) oxide nanoparticles with a $\mathrm{KCl}-\mathrm{Glycol}-\mathrm{PHPA}$ polymerbased mud used in drilling operation. Journal of Petroleum Exploration and Production Technology, 10(8), pp.3389-3397. Available at:

http://dx.doi.org/10.1007/s13202-020-00933-1.

Alfa, A. K., 2019. Siderite as a Weighting Material in Drilling Mud. BAU Journal Science and Technology, 1(1). Available at: https://digitalcommons.bau.edu.lb/ stjournal/vol1/iss1/1.

Cordes, E.E. et al., 2016. Environmental Impacts of the Deep-Water Oil and Gas Industry: A Review to Guide Management Strategies. Frontiers in Environmental Science, 4. Available at:

http://dx.doi.org/10.3389/fenvs.2016.00058.

Doric, B. \& Dimovski, V., 2018. Managing petroleum sector performance - a sustainable administrative design. Economic Research-Ekonomska Istraživanja, 31(1), pp.119-138. Available at:

http://dx.doi.org/10.1080/1331677x.2017.1421995.

Gamal, H. et al., 2019. Effect of pH on Rheological and Filtration Properties of WaterBased Drilling Fluid Based on Bentonite. Sustainability, 11(23), p.6714. Available at: http://dx.doi.org/10.3390/su11236714.

Gandhi, S.M. \& Sarkar, B.C., 2016. Drilling. Essentials of Mineral Exploration and Evaluation, pp.199-234. Available at: http://dx.doi.org/10.1016/b978-0-12-805329-4.00015-6.

Hossain, M.E. \& Islam, M. R., 2018. Problems Related to the Mud System. Drilling Engineering Problems and Solutions, pp.77-137. Available at: http://dx.doi.org/10.1002/9781118998632.ch3.

Jayasinghe, C.D. \& Jayawardena, U.A., 2019. Toxicity Assessment of Herbal Medicine Using Zebrafish Embryos: A Systematic Review. Evidence-Based Complementary and Alternative Medicine, 2019, pp.1-17. Available at: http://dx.doi.org/10.1155/2019/7272808.

Kark, S. et al., 2015. Emerging conservation challenges and prospects in an era of offshore hydrocarbon exploration and exploitation. Conservation Biology, 29(6), pp.1573-1585. Available at

http://dx.doi.org/10.1111/cobi.12562.

Modarresi Chahardehi, A., Arsad, H. \& Lim, V., 2020. Zebrafish as a Successful Animal Model for Screening Toxicity of Medicinal Plants. Plants, 9(10), p.1345. Available at: http://dx.doi.org/10.3390/plants9101345.

Neff, J.M., 2008. Estimation of Bioavailability of Metals from Drilling Mud Barite. Integrated Environmental Assessment and Management, 4(2), p.184. Available at: http://dx.doi.org/10.1897/ieam_2007-037.1.

Sarmah, S. \& Marrs, J., 2016. Zebrafish as a Vertebrate Model System to Evaluate Effects of Environmental Toxicants on Cardiac Development and Function. International Journal of Molecular Sciences, 17(12), p.2123. Available at: http://dx.doi.org/10.3390/ijms17122123.

Sarmah, S. \& Marrs, J.A., 2013. Complex cardiac defects after ethanol exposure during discrete cardiogenic events in zebrafish: Prevention with folic acid. Developmental Dynamics, 242(10), pp.1184-1201. Available at:

http://dx.doi.org/10.1002/dvdy.24015. 
Seyedmohammadi, J., 2017. The effects of drilling fluids and environment protection from pollutants using some models. Modeling Earth Systems and Environment, 3(1). Available at:

http://dx.doi.org/10.1007/s40808-017-0299-7.

Sharif MD, A. et al., 2017. Drilling Waste Management and Control the Effects. Journal of Advanced Chemical Engineering, 07(01). Available at:

http://dx.doi.org/10.4172/2090-4568.1000166.
Zhu, X. et al., 2008. Comparative toxicity of several metal oxide nanoparticle aqueous suspensions to Zebrafish (Danio rerio) early developmental stage. Journal of Environmental Science and Health, Part A, 43(3), pp.278-284. Available at: http://dx.doi.org/10.1080/10934520701792779. 